\section{A new research journal to understand the interactions of xenobiotics with living organisms}

Since its creation in January 2011, the Journal of Xenobiotics (published by PAGEPress, Italy) is devoted to the publication of novel research articles in the fields of the occurrence and biochemical effects of xenobiotics on all living organisms. Although xenobiotics are defined firstly as compounds that are foreign to life, compounds of natural origins occuring at concentrations that are not usually found, could also be considered as foreigners since their enhanced occurrence may affect non-target organisms. In this sense, products derived from natural products are well known to have either a beneficial (natural products used as food additives and many pharmaceuticals) or detrimental (cyanotoxins) impact on the health of an organism. The journal recognizes that these compounds could be either harmful or beneficial to organisms and the interplay between these two aspects is of particular interest.

The Journal of Xenobiotics is, therefore, dedicated to the rapid publication of peerreviewed research articles dealing with either pharmacological or toxicological properties of foreign compounds on all living beings. We think that this dualistic approach will provide a more dynamic perspective on the fundamental properties of xenobiotics towards life processes. Indeed, the nature of the interaction of a compound at the biochemical level will likely dictate the biological outcome of exposure. In this sense, the scope of the Journal encompasses the fundamental biochemical properties of xenobiotics. Furthermore, organisms are seldom exposed to single compounds in nature, besides situations of acute exposure to high levels of a given contaminant (e.g., industrial spills) or during therapeutic treatments of various health problems (e.g., acute infections, hypertension, cancer treatments). The understanding of the cumulative effects of mixtures is particularly of interest, given the socio-economic context of the $21^{\text {st }}$ century. For example, the use of nanotechnology-derived drug vectors, adopted to increase the therapeutic efficacy of drugs, could be released in the environment and could interact with other existing contaminants (polyaromatic hydrocarbons, flame retardants, metals, etc.), thereby influencing their bioavailability. As another example, global warming is expected to increase rainfall events in some areas, thereby developing rainfall overflows and the release of untreated urban wastewaters in the aquatic environment. This highlights the need to understand the effects of mixtures on organ- isms and it calls for new and complex methods to better understand these complex issues. High throughput approaches (derived from omics) are complex tools to address several difficult questions of the $21^{\text {st }}$ century. These approaches will increase the diagnostic power of biomarkers not only in understanding the mode of action and identifing outcome pathways in cells, but also in better understanding the toxic or pharmacologic at fingerprint of complex mixtures in organisms.

In this regard, the Aims and Scope of the Journal of Xenobiotics have been proposed to give flexibility in order to address both the

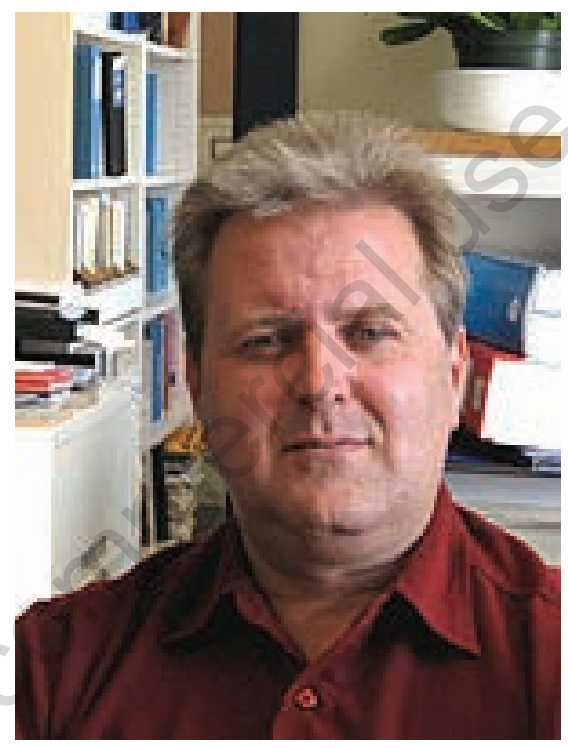

Our Editor in Chief. François Gagné has been a Senior biochemical eco-toxicologist at Environment Canada since 1994. He received his academic training in biochemistry and earned his PhD (1996) in environmental toxicology at the University of Metz in France. He has published more than 150 papers on ecotoxicology in international scientific journals and books. He currently holds invited and associated professorships at INRS-Armand-Frappier Institute and the Marine Science Institute at the University of Québec at Rimouski. His field of research is mainly focused on the understanding of the molecular mode of action of miscellaneous emerging substances in non-target aquatic organisms, such as products derived from oil sands, toxins, pharmaceuticals, and nanotechnology. He is also involved in the study of new emerging methods (metabolomics and transcriptomics) to develop novel indicators of toxicity for risk assessment and projects dealing with the cumulative effects of multiple stressors.
Correspondence: François Gagné,

Editor in Chief, Journal of Xenobiotics, Environment, Canada, 105 Mc Gill, Montréal, Québec, Canada.

E-mail: Francois.gagne@ec.gc.ca

This work is licensed under a Creative Commons Attribution NonCommercial 3.0 License (CC BYNC 3.0).

(C) Copyright F. Gagné, 2012

Licensee PAGEPress, Italy

Journal of Xenobiotics 2012; 2:e8

doi:10.4081/xeno.2012.e8

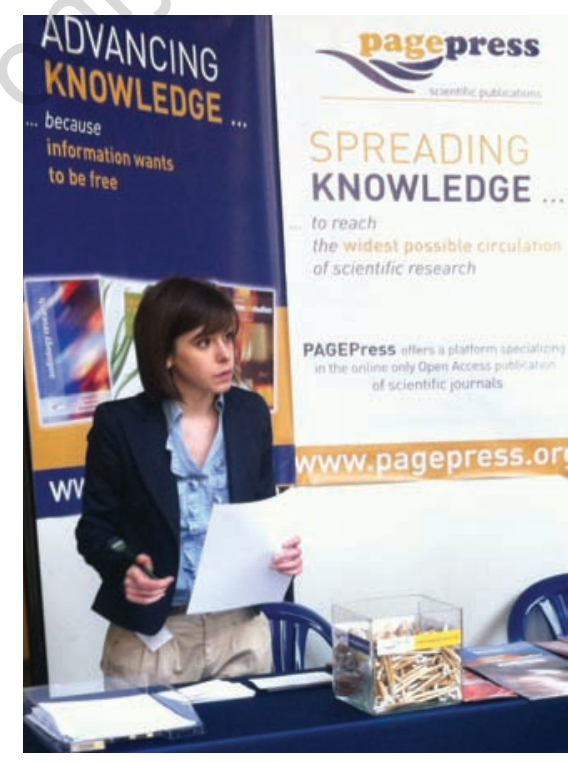

Our Managing Editor. Paola Granata is one of the Junior Managing Editors at PAGEPress. After graduating in Intercultural and Multimedia Communication at the University of Pavia, Italy, she started working in publishing while she was a university student. In 2010, she arrived at PAGEPress where she has been able to widen her editorial skills and experience, contributing to the launch and the growth of several brand new journals. Currently supported by an efficient and invaluable Editorial Staff, she is involved in the management of over 30 journals in the PAGEPress portfolio, like the Journal of Xenobiotics, leading Editors, Authors, Reviewers and other actors through the technical editorial process. 
beneficial and harmful properties of new and existing compounds in various organisms. Furthermore, natural compounds produced at concentrations not found in nature are also defined as per the classical meaning of xenobiotics. Being an Open Access journal, it will also promote the accessibility of published articles among the scientific community including research professionals and students in the most efficient manner. In an attempt to achieve the highest quality of publications of this multidisciplinary journal, we appointed an Editorial Board including worldwide recognized experts in different fields, such as: natural and herbal medicinal products, drug therapeutics and biotransformation, clinical safety, occurrence and persistence of xenobiotics in the environment, nanotoxicology and environmental toxicology. We aim to created as much as possible a global perspective by selecting Board Members from each continent in the major disciplines given above, in an attempt to offer a broader perspective on all the various issues pertaining to xenobiotics and to establish a truly international peer-reviewed Open Access Journal.
The managing committee of this journal is headed by Ms Paola Granata, a member of the efficient managerial team, who ensures that all steps of submission, peer-review and final preparation of proofs respect the journal publication schedules and deadlines. The Journal also has an in-house English copyeditor to assist authors whose native language is not English. All these factors make the Journal of Xenobiotics a convivial, simple and rapid platform for research papers.

The Journal of Xenobiotics is a new 0pen Access journal involved in the spreading of peer-reviewed research articles or short communications dealing with the presence and the biological effects of xenobiotics. It is a young but dynamic international journal that aims to reach the scientific community worldwide as much as possible. We are confident that our journal will continue to grow in the future and that it will contribute to the understanding of the beneficial and harmful properties of chemicals as the result of human activities.

François Gagné Editor in Chief

\section{PAGEPress, our publisher}

PAGEPress is an Italian scientific publisher that has been developing services for the international scientific community since 1992 . The concept of Open Access publishing has been hugely successful in recent years and continues to make a significant contribution to the spreading of knowledge in the field of medicine and science. Our goal is to become an international publisher and provider of Open Access academy journals in a variety of scientific fields, such as medicine, biology, zoology, agriculture, and many others.

The Journal of Xenobiotics shares this mission and aims to become one of the most recognized Open Access journals in its field. All the articles published in PAGEPress journals, and the Journal of Xenobiotics, as with all, undergo a high-quality peer-review system and are published online just as soon as they have been accepted and have the editorial process. The published articles are also widely distributed among the main online directories, making them accessible worldwide, by providing access to the scientific literature to anyone, anywhere, by publishing works from every nation, and by engaging a geographically diverse group of scientists in the editorial process. 